Research report

\title{
Effects of acetylcholine and cholinergic antagonists on the activity of nucleus of the solitary tract neurons
}

\author{
Werner I. Furuya ${ }^{a}$, Eduardo Colombari ${ }^{a}$, Alastair V. Ferguson ${ }^{\text {b,1 }}$, Débora S.A. Colombari ${ }^{a, 1, *}$ \\ ${ }^{a}$ Department of Physiology and Pathology, School of Dentistry, São Paulo State University, Araraquara, SP, Brazil \\ ${ }^{\mathrm{b}}$ Department of Biomedical and Molecular Sciences, School of Medicine, Queen's University, Kingston, ON, Canada
}

\section{A R T I C L E I N F O}

\section{Article history:}

Received 3 August 2016

Received in revised form 11 January 2017

Accepted 21 January 2017

Available online 25 January 2017

\section{Keywords:}

Nicotinic receptors

Muscarinic receptors

Acetylcholine

Patch clamp

\begin{abstract}
A B S T R A C T
Previously we have demonstrated that microinjection of acetylcholine (ACh) into the intermediate nucleus of the solitary tract (iNTS) induced sympatho-inhibition combined with a decrease in the phrenic nerve activity (PNA), whereas in the commissural NTS (cNTS), ACh did not change sympathetic nerve activity (SNA), but increased the PNA. In view of these demonstrated distinctive effects of ACh in different subnuclei of the NTS the current studies were undertaken to examine, using patch clamp techniques, the specific effects of ACh on the excitability of individual neurons in the NTS, as well as the neuropharmacology of these actions. Coronal slices of the brainstem containing either cNTS or iNTS subnuclei were used, and whole cell patch clamp recordings obtained from individual neurons in these two subnuclei. In cNTS, $58 \%$ of recorded neurons $(\mathrm{n}=12)$ demonstrated rapid reversible depolarizations in response to ACh $(10 \mathrm{mM})$, effects which were inhibited by the nicotinic antagonist mecamylamine $(10 \mu \mathrm{M})$, but unaffected by the muscarinic antagonist atropine $(10 \mu \mathrm{M})$. Similarly, bath application of ACh depolarized $76 \%$ of iNTS neurons $(n=17)$, although in this case both atropine and mecamylamine reduced the AChinduced depolarization. These data demonstrate that ACh depolarizes cNTS neurons through actions on nicotinic receptors, while depolarizing effects in iNTS are apparently mediated by both receptors.
\end{abstract}

(c) 2017 Elsevier B.V. All rights reserved.

\section{Introduction}

The nucleus of the solitary tract (NTS) is an important medullary area that receives peripheral afferent information from cardiovascular and respiratory systems (Ciriello et al., 1994; Cottle, 1964; Palkovits and Zaborsky, 1977). Baroreceptors make their first synapse mainly at the level of the intermediate subnucleus of the NTS (iNTS; Ciriello et al., 1994), while peripheral chemoreceptors project primarily to the commissural subnucleus of the NTS (cNTS; Ciriello et al., 1994). Functional data have demonstrated that lesions of the iNTS abolish the baroreflex, whereas cNTS lesions impair the pressor and bradycardia induced by chemoreceptor activation, leaving the baroreflex unchanged (Blanch et al., 2013; Colombari et al., 1996; Miura and Reis, 1972; Schreihofer et al., 1999).

Although L-glutamate has been proposed as the major excitatory neurotransmitter released by the baro- and chemoreceptors afferent inputs in the NTS (Machado, 2001; Talman et al., 1980),

\footnotetext{
* Corresponding author at: Department of Physiology \& Pathology, School of Dentistry of Araraquara, UNESP Rua Humaitá, 1680, Araraquara 14801-903, SP, Brazil.

E-mail address: deborac@foar.unesp.br (D.S.A. Colombari).

1 DSAC and AVF are co-seniors.
}

a number of other neurotransmitters, such as dopamine, GABA, substance $\mathrm{P}$, angiotensin II and acetylcholine ( $\mathrm{ACh}$ ), have been suggested to contribute to the neurotransmission of cardiorespiratory signals in the NTS (Abdala et al., 2006; Andresen and Kunze, 1994; Criscione et al., 1983; da Silva et al., 2008; Furuya et al., 2014; Sapru, 1996; Tsukamoto et al., 1994). Choline acetyltransferase positive neurons, high choline acetyltransferase and acetylcholinesterase activity, muscarinic and nicotinic receptors are found in the NTS (Cheng et al., 2011; Ernsberger et al., 1988; Gotts et al., 2015; Helke et al., 1983; Simon et al., 1981; Wada et al., 1989). In fact, microinjection of ACh or the muscarinic agonist carbachol into the iNTS of anaesthetized or awake rats induces dose-dependent baroreflex-like hypotensive and bradycardic responses (Criscione et al., 1983; da Silva et al., 2008; Tsukamoto et al., 1994). Similar responses are also produced by nicotinic receptor activation in the iNTS (Dhar et al., 2000). More recently, we have shown that the microinjection of ACh in the iNTS produced sympatho-inhibitory responses and reduced phrenic frequency, whereas in cNTS microinjections of ACh did not change the sympathetic nerve activity (SNA), but increased the PNA (Furuya et al., 2014). In this study, we also demonstrated that pretreatment with mecamylamine (nicotinic antagonist) abolished all the effects of ACh injected into the iNTS or the cNTS, whereas 
atropine (muscarinic antagonist) reduced only the effects of ACh injected into the cNTS (Furuya et al., 2014).

Cell recording studies have shown that ACh changes the current of NTS neurons. For instance, in medullary horizontal slices, ACh increases the firing frequency of iNTS neurons, and such effects are reduced by both muscarinic and nicotinic receptors blockade (Shihara et al., 1999). In the same study, it was demonstrated that muscarinic receptor activation inhibits $\mathrm{K}^{+}$channels, while nicotinic activation promotes $\mathrm{Na}^{+} / \mathrm{K}^{+}$channels opening (Shihara et al., 1999; Shiraki et al., 1997). In another study, using NTS cell culture from neonatal rats, it was found that both ACh and nicotine induced depolarizing current (Ueno et al., 1993). While these data demonstrate that ACh depolarizes iNTS cells, resulting in increased firing frequency, to date studies have not compared the effects of ACh on distinct NTS subnuclei. Given the different physiological responses elicited by ACh in iNTS and cNTS, the present study was undertaken to examine both the cellular effects and neuropharmacology of ACh in these NTS subnuclei.

\section{Results}

\subsection{Acetylcholine depolarizes cNTS neurons}

We first examined the effects of $10 \mathrm{mM} \mathrm{ACh}$ ( 1 min bath perfusion) on the membrane potential of 12 cNTS neurons. The majority of these cells (7/12-58\%) showed rapid, reversible depolarizations (mean $6.9 \pm 1.5 \mathrm{mV}$ ) as illustrated in Fig. 1C-E, while the remaining 5 neurons tested were unaffected. $(-0.0 \pm 0.7 \mathrm{mV})$. The $1.0 \mathrm{mM}$ concentration of ACh depolarized 2 out of 4 cNTS neurons, and the magnitude of the depolarizations observed was smaller $(4.5 \pm 1.2 \mathrm{mV})$, (Fig. 1B, D-E). Finally, at a concentration of $0.1 \mathrm{mM} A C h$, no significant effects were observed on the membrane potential of 4 neurons tested (Fig. 1A, D-E).

Next, we examined the ability of cholinergic antagonists to modulate these depolarizing effects of ACh on cNTS neurons. In a group of 7 neurons which showed clear depolarizing effects of ACh before bath administration of atropine (ATR; $10 \mu \mathrm{M}, 5 \mathrm{~min}$ ), responses to a subsequent similar administration of $\mathrm{ACh}$ were unaffected $(7.6 \pm 2.6 \mathrm{mV}$ before ATR vs. $6.7 \pm 1.9 \mathrm{mV}$ after ATR, $\mathrm{p}>0.05, \mathrm{n}=7$ ) as illustrated in Fig. $2 \mathrm{~A}$ and $\mathrm{C}$. In $5 \mathrm{ACh}$ responsive cNTS neurons mecamylamine (MEC; $10 \mu \mathrm{M}, 5 \mathrm{~min}$ ) administration completely abolished the effects of a second application of ACh $(10.4 \pm 2.7 \mathrm{mV}$ before MEC vs. $1.3 \pm 0.9 \mathrm{mV}$ after MEC, $\mathrm{p}<0.05$, $\mathrm{n}=5$ ), as illustrated in Fig. $2 \mathrm{~B}$ and $\mathrm{C}$. The cholinergic antagonists alone did not change the resting membrane potential of cNTS neurons.

\subsection{Acetylcholine depolarizes iNTS neurons}

We next examined the effects of $10 \mathrm{mM}$ ACh administered for 1 min by bath perfusion on the membrane potential of 17 iNTS neurons. The majority of these cells (13/17-76\%) showed rapid, reversible depolarizations (mean $9.8 \pm 2.4 \mathrm{mV}$ ) as illustrated in Fig. 3C-D, while the remaining 4 neurons tested were unaffected. $(-0.5 \pm 0.8 \mathrm{mV})$. As in the cNTS, the $1.0 \mathrm{mM}$ concentration of ACh induced depolarization in 2 out of 7 iNTS neurons, and the magnitude of the responses observed were also smaller $(3.9 \pm 1.7 \mathrm{mV})$, (Fig. 3B, D-E). Finally, at a concentration of $0.1 \mathrm{mM} \mathrm{ACh}$, no significant effects were observed on the membrane potential of 6 neurons tested (Fig. 3A, D-E).

Next, we examined the ability of cholinergic antagonists to modulate these depolarizing effects of ACh on iNTS neurons. In a group of 8 neurons which showed clear depolarizing effects of ACh before bath administration of atropine $(10 \mu \mathrm{M}, 5 \mathrm{~min})$, responses to a subsequent similar administration of ACh resulted in a significantly reduced depolarizing effect ( $12.5 \pm 2.8 \mathrm{mV}$ before
ATR vs. $7.8 \pm 2.4 \mathrm{mV}$ after ATR, $\mathrm{p}<0.05, \mathrm{n}=8$ ) as illustrated in Fig. $4 \mathrm{~A}$ and $\mathrm{C}$ ). Similar recordings from $\mathrm{ACh}$ responsive iNTS neurons showed that mecamylamine $(10 \mu \mathrm{M}, 5 \mathrm{~min})$, administration almost completely abolished the effects of a second application of ACh on these neurons $(9.5 \pm 2.0 \mathrm{mV}$ before MEC vs. $2.9 \pm 1.0 \mathrm{mV}$ after MEC, $\mathrm{p}<0.05, \mathrm{n}=8$ ), as illustrated in Fig. $4 \mathrm{~B}$ and $\mathrm{C}$. The cholinergic antagonists alone did not change the resting membrane potential of iNTS neurons.

\section{Discussion}

In the present study, we demonstrated, using whole cell patch clamp techniques, depolarizing effects of ACh on the majority of neurons recorded from NTS slices. These effects were observed in both iNTS and cNTS and were found to be rapid, reversible and concentration dependent. A significant proportion of NTS neurons were also found to be non-responsive, and it should be noted that no hyperpolarizations were seen. The nicotinic receptor antagonist mecamylamine, inhibited the responses to ACh in both iNTS and cNTS, suggesting roles for these receptors in both regions. In contrast, the muscarinic antagonist atropine inhibits the ACh actions in the iNTS, but was without effect in the cNTS, suggesting a region-specific functional role for the muscarinic receptor in iNTS.

Nicotinic and muscarinic receptors have been found in the NTS (Cheng et al., 2011; Ernsberger et al., 1988; Gotts et al., 2015; Wada et al., 1989), although the differential localization within the cNTS and iNTS of both receptors were not systematically studied using either immunohistochemical or receptor autoradiography protocols. In the present study, it was observed that in the cNTS, the ACh evoked response was blocked by nicotinic receptors, while atropine did not change the depolarizing effect of ACh. In a previous study using the in situ preparation, we have observed that ACh in the cNTS does not alter SNA, but increase the PNA and changed the sympatho-respiratory coupling (Furuya et al., 2014). In that study, at equimolar doses, atropine reduced and mecamylamine blocked the tachypnea induced by ACh in the cNTS, whereas only the nicotinic receptor blockade was able to revert the change in sympatho-respiratory coupling induced by ACh in the cNTS (Furuya et al., 2014) and to reduce the peripheral chemoreceptor-induced tachypnea (Furuya et al., 2014). Therefore, even though in the in situ studies muscarinic receptors in the cNTS might have a role in mediating ACh-induced responses, it seems that nicotinic receptors have a more prominent effect on $\mathrm{ACh}$, similarly to the present data.

Functional studies have demonstrated pre- and post- synaptic nicotinic receptors (Feng et al., 2012; Feng and Uteshev, 2014; Kalappa et al., 2011) in the cNTS. These studies demonstrated that in the cNTS nicotine application can activate cNTS neurons either by increasing glutamatergic synaptic release, or by direct somatodendritic activation. In addition, it seems that depending on the cNTS projection area of the brain, the responsiveness to nicotine is pre-or post-synaptically mediated (Feng et al., 2012; Feng and Uteshev, 2014). Thus, the present and previous studies (Feng et al., 2012; Feng and Uteshev, 2014; Kalappa et al., 2011), reiterate the role of nicotinic receptors in the cNTS in mediating the effects of ACh in the cNTS. The present study does not however clarify whether such effects are a consequence of presynaptic of somatodendritic actions of ACh.

Both nicotinic and muscarinic receptors seem to be involved on the ACh depolarizing responses in the iNTS, as demonstrated by the present and other studies (Shihara et al., 1999). However, in the present study atropine reduced while mecamylamine blocked the depolarizing effects of ACh in the iNTS. In an in situ preparation, we have demonstrated that $A C h$ in the iNTS decrease SNA and PNA and both responses were totally blocked by mecamylamine, while atropine at equimolar dose, was not 

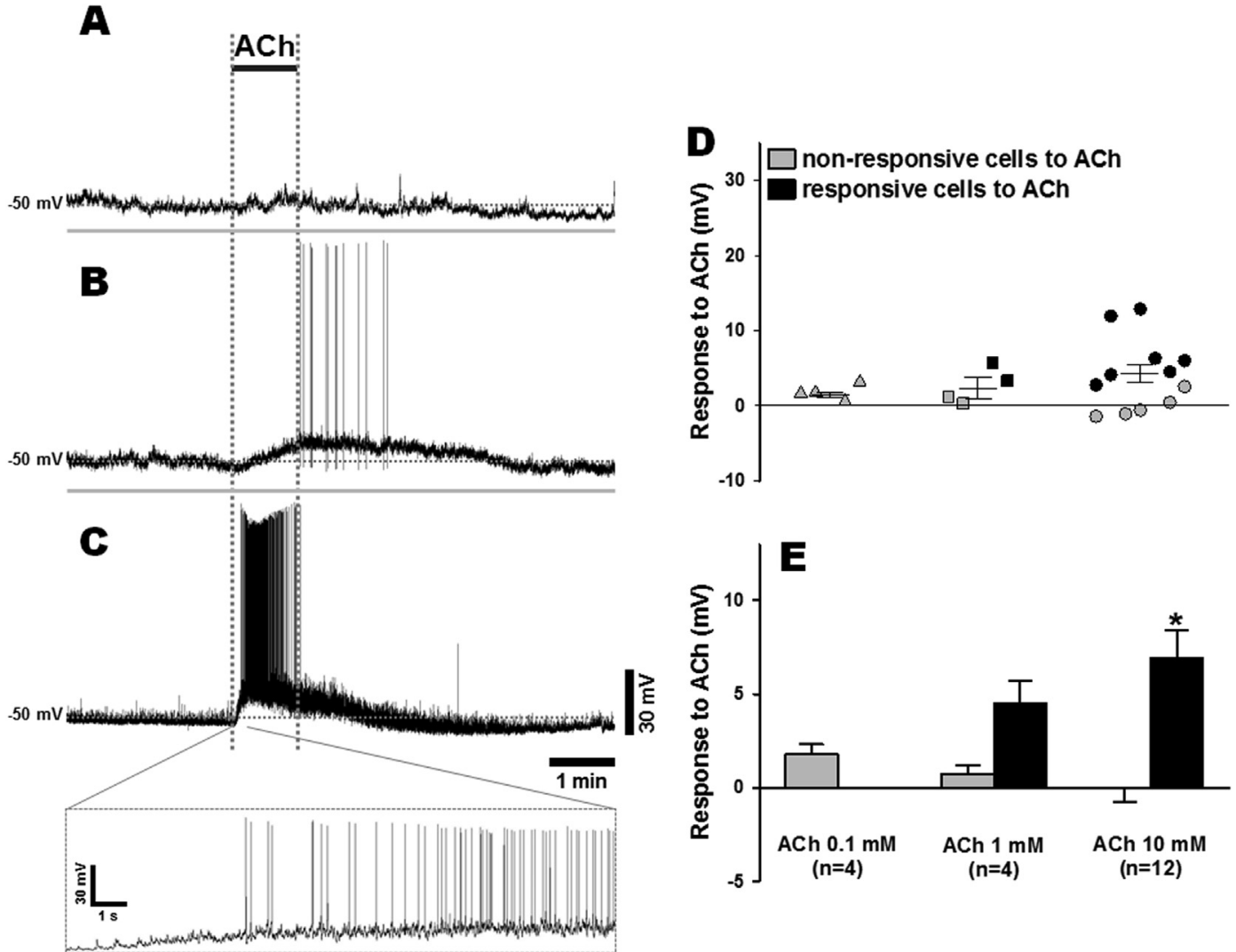

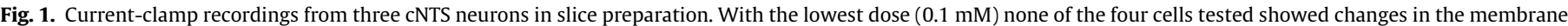

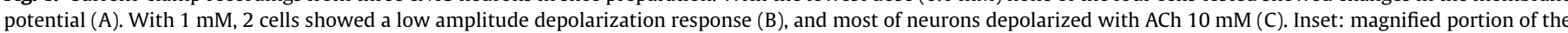

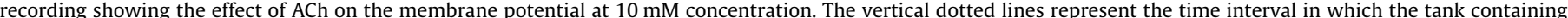

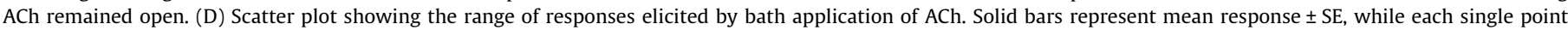

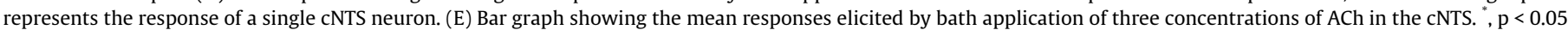
vs. non-responsive cells to ACh. Group data are expressed as mean $\pm \mathrm{SEM}, \mathrm{p}<0.05, t$ test.
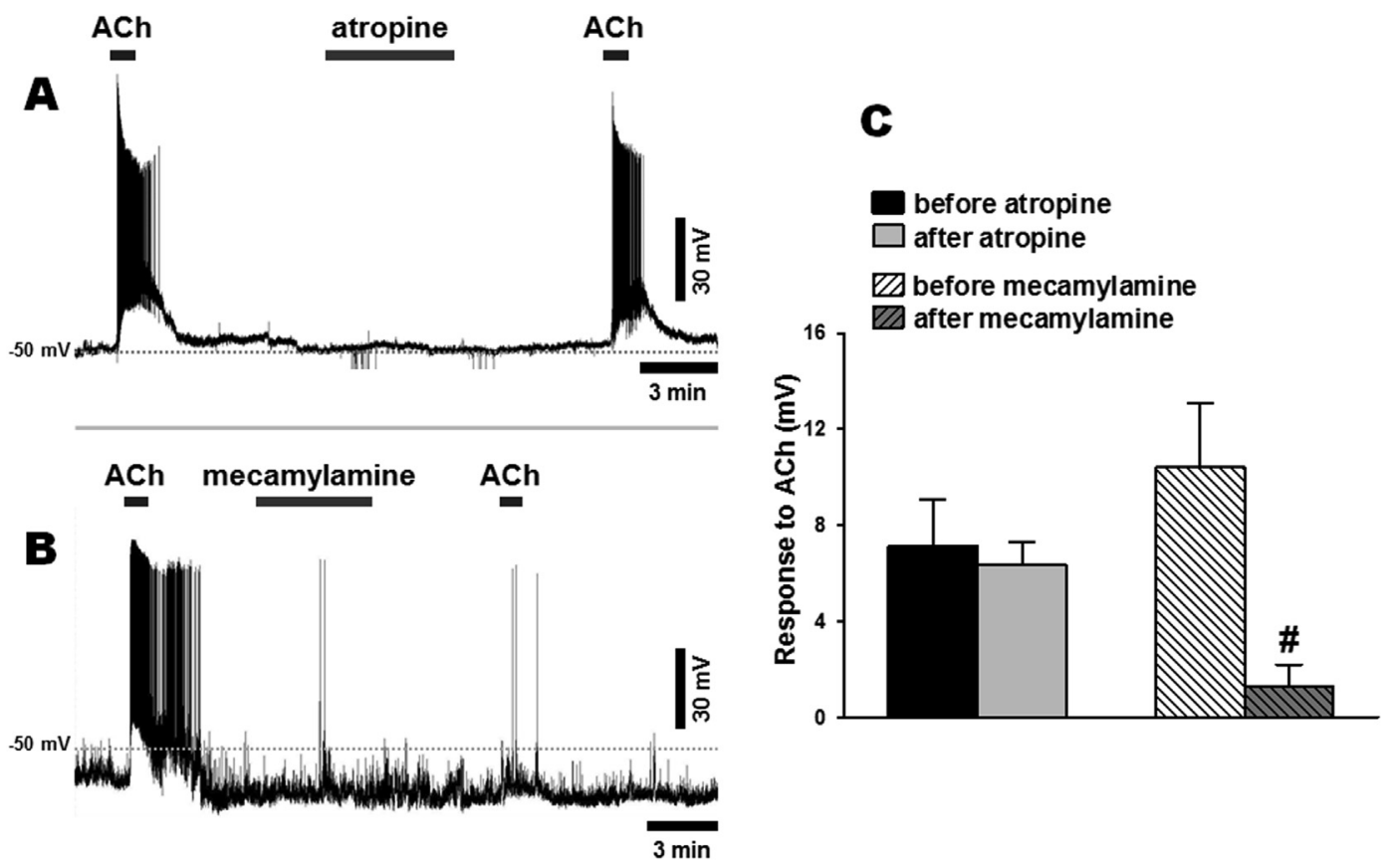

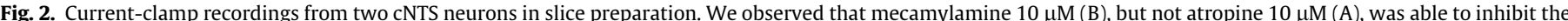

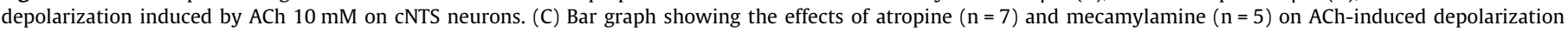
response of cNTS neurons. \#, $\mathrm{p}<0.05 \mathrm{vs}$. before mecamylamine $10 \mu \mathrm{M}$. Group data are expressed as mean $\pm \mathrm{SEM}$, $\mathrm{p}<0.05$, paired $t$ test. 

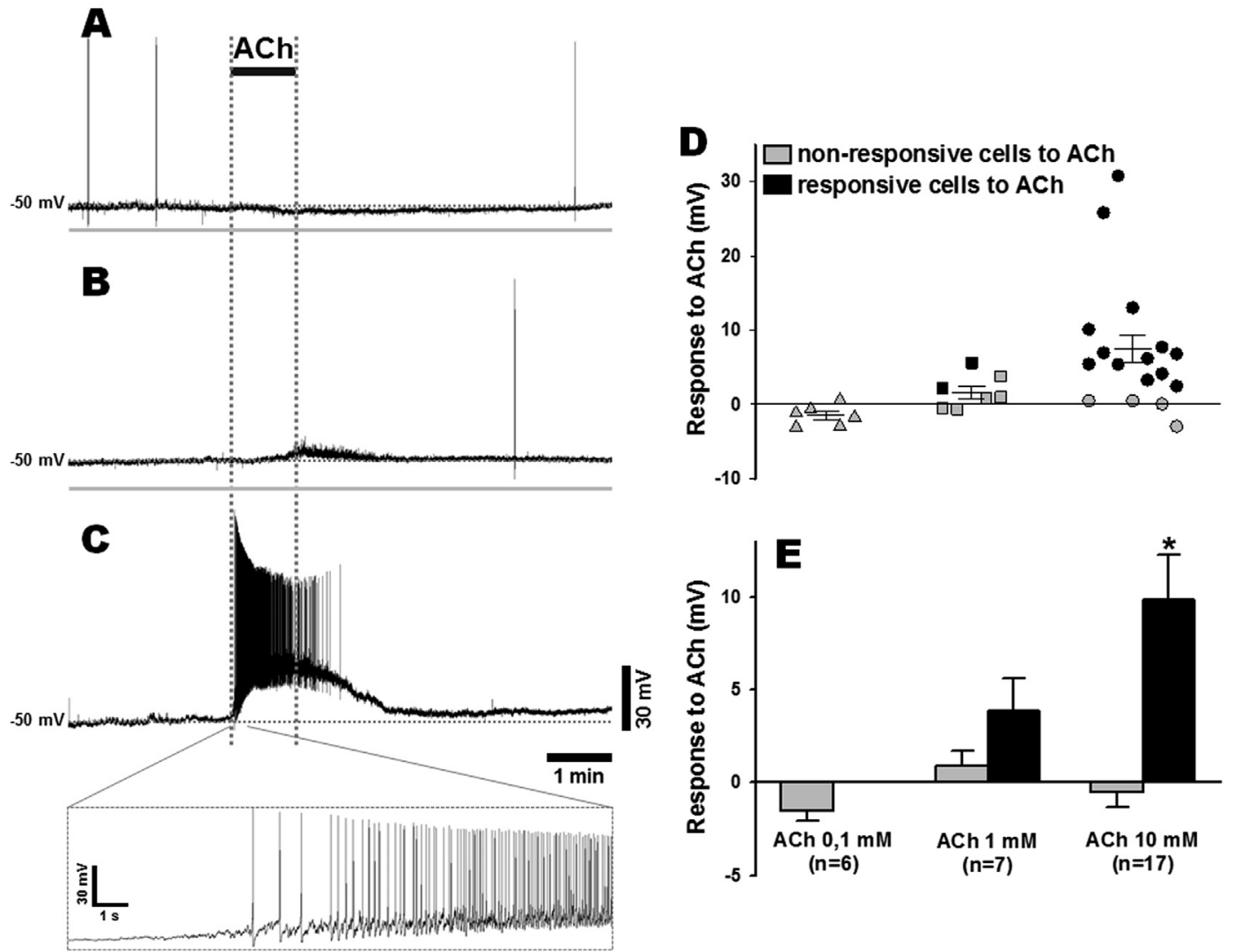

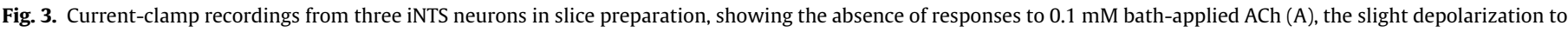

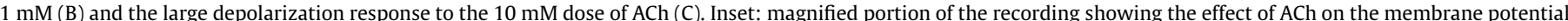

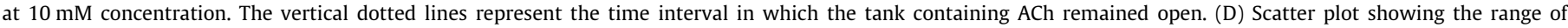

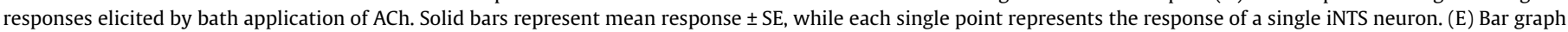

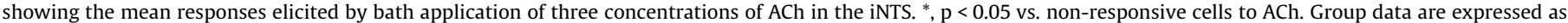
mean \pm SEM, $\mathrm{p}<0.05$, $t$ test.

effective in changing this response (Furuya et al., 2014). The reason for this difference between the in situ and in vitro responses to cholinergic antagonists are not known. It is possible, that in the in situ preparation, a higher dose of atropine would be able to reduce the effects of ACh on SNA and PNA. In fact, preliminary data from our laboratory demonstrated that a higher dose of ATR was able to reduce the decrease of SNA and PNA. We have shown that the reduction of SNA induced by baroreflex activation was not affected by bilateral microinjections of either nicotinic or muscarinic antagonists into the iNTS (Furuya et al., 2014), suggesting that ACh induces SNA changes acting on pathways not related to baroreflex function. Thus, although the data presented here clearly show that the depolarizing effects of ACh in the iNTS neurons involve the participation of both muscarinic and nicotinic receptors, it should be emphasized that they provide no direct information regarding the functional consequences of such actions.

In conclusion, these data demonstrate that ACh depolarizes cNTS neurons through actions on nicotinic receptors while depolarizing effects in iNTS are apparently mediated by both receptors. These observations correlate well with previous studies, and in combination suggest that these neurons might be involved in the cardiorespiratory changes induced by ACh in the iNTS and the cNTS.

\section{Experimental procedures}

\subsection{Animals}

Male Sprague-Dawley rats weighing 60-100 g (p21-28) were used in this study. All procedures conformed to the ethical guidelines established by the Canadian Council on Animal Care and were approved by the Queen's University Animal Care Committee.

\subsection{Preparation of brainstem slices}

The animals were decapitated and their brains quickly removed and immersed in a high sucrose based ice cold slicing solution (2$4{ }^{\circ} \mathrm{C}$ ) containing (in $\mathrm{mM}$ ): $\mathrm{NaCl} 87, \mathrm{KCl} 2.5, \mathrm{NaHCO}_{3} 25, \mathrm{CaCl}_{2} 0.5$, $\mathrm{MgCl}_{2} 7, \mathrm{NaH}_{2} \mathrm{PO}_{4} 1.25$, glucose 25 and sucrose 75 , gassed with $95 \% \mathrm{O}_{2}$ and $5 \% \mathrm{CO}_{2}$, for 3-5 min. The region of brainstem containing the NTS was isolated and mounted onto a vibratome (Leica Microsystems, Nussloch, Germany), and immersed in the same slicing solution gassed with $95 \% \mathrm{O}_{2}$. Taking the calamus scriptorius and the area postrema (AP) as landmarks, $300-\mu \mathrm{m}$ coronal slices were cut $600-700 \mu \mathrm{m}$ caudal and to $600-700 \mu \mathrm{m}$ rostral to calamus scriptorius, resulting in 4 slices. The first two slices contained the cNTS region, which is located caudal to AP, while the last two slices contained the iNTS with the presence of the AP in the slices. Slices were then incubated in artificial cerebrospinal fluid

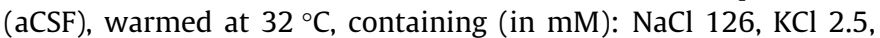
$\mathrm{NaHCO}_{3} 26, \mathrm{CaCl}_{2} 2, \mathrm{MgCl}_{2} 2, \mathrm{NaH}_{2} \mathrm{PO}_{4} 1.25$ and glucose 10 , gassed with $95 \% \mathrm{O}_{2}$ and $5 \% \mathrm{CO}_{2}$, for minimum $1 \mathrm{~h}$ before recording.

\subsection{Electrophysiology}

Slices were placed in a recording chamber and continuously perfused with $30-32{ }^{\circ} \mathrm{C}$ oxygenated aCSF at a rate of approximately $2 \mathrm{~mL} / \mathrm{min}$. Neurons were visualized on an upright differential 

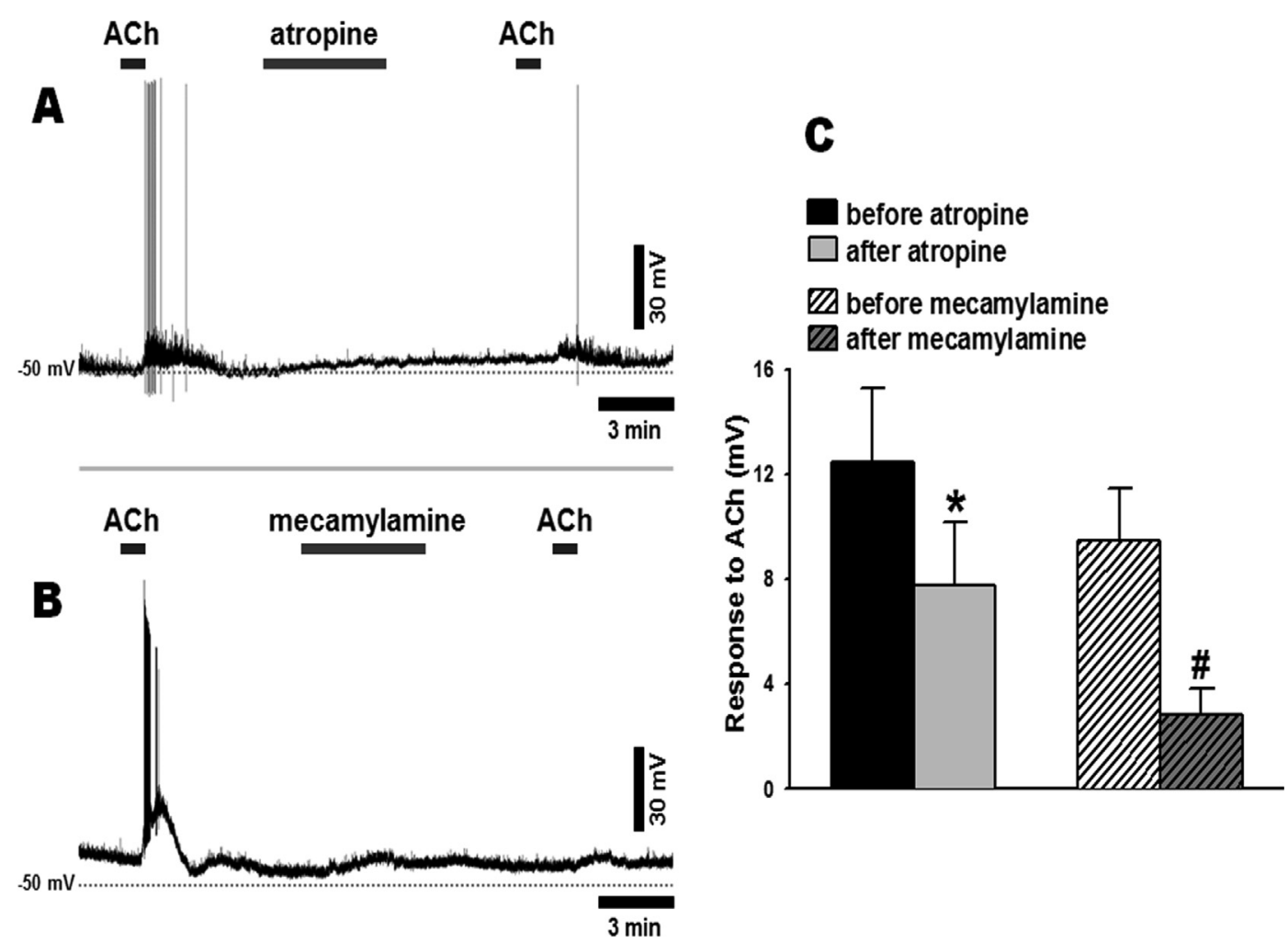

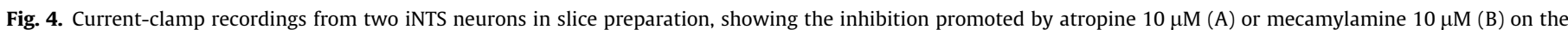

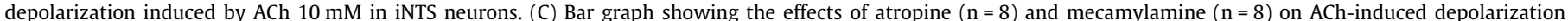

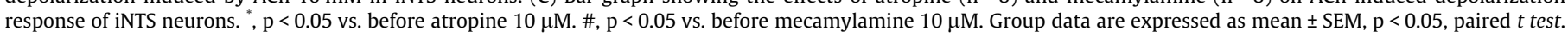

interface contrast microscopy system (Nikon, Tokyo, Japan). Recording electrodes were prepared from glass micropipettes (World Precision Instruments, Sarasota, FL), pulled on a Sutter Instruments P97 micropipette puller and filled with an intracellular solution made of (in $\mathrm{mM}$ ): potassium gluconate $125, \mathrm{KCl} 10$, $\mathrm{MgCl}_{2} 2, \mathrm{CaCl}_{2}$ 0.1, EGTA 5.5, HEPES 10 and NaATP 2, pH 7.2, adjusted with $\mathrm{KOH}$. When filled with the intracellular solution, electrodes had resistances between 3-5 M $\Omega$. After a highresistance seal (up to $1 \mathrm{G} \Omega$ ) had been established, brief suction was applied to rupture the membrane and achieve whole cell configuration. Whole cell recordings were obtained and filtered at $2.4 \mathrm{kHz}$ using a Multiclamp 700B amplifier (Molecular Devices, Sunnyvale, $\mathrm{CA}$ ), and signals were digitized using a sampling rate of $5 \mathrm{kHz}$, using a Micro 1401 interface, and data were collected with Spike2 software for offline analysis (Cambridge Electronic Devices, Cambridge, UK). Only those cells which had action potentials larger than $60 \mathrm{mV}$ and a stable baseline membrane potential after 10 min were included in our analysis. In order to determine a concentration response curve and investigate the neuropharmacology of ACh actions in the NTS a minimum $100 \mathrm{~s}$ stable baseline membrane potential recording was obtained from all neurons prior to bath administration of ACh and antagonists. ACh, at concentrations of $0.1,1$ and $10 \mathrm{mM}$, was then sequentially applied by bath perfusion for 1 min periods, separated by recovery time of at least 6 min between applications, and membrane potential recorded. The response was determined by comparing the mean membrane potential of the neuron before and after application of the ACh. A response was considered significant if the change in membrane potential after ACh application was at least twice the amplitude of the standard deviation of the baseline membrane potential obtained during a 100 -s period immediately before ACh application. Post application membrane potential was the peak membrane potential averaged over a 100-s period of the recording showing a maximal effect. This method of analysis provides a consistent, unbiased evaluation of effects ACh on each neuron based on the variability of the baseline membrane potential of that neuron. Neurons were excluded from analysis if they did not show a recovery towards baseline following ACh wash out from the bath.

Once we established the most appropriate dose of $\mathrm{ACh}$, we tested the effects of cholinergic antagonists atropine (ATR, nonselective muscarinic antagonist) or mecamylamine (MEC, nonselective nicotinic antagonist) on the effects of $\mathrm{ACh}$ in the neurons of iNTS and cNTS. The dose for the antagonists was $10 \mu \mathrm{M}$ for both ATR (Shihara et al., 1999), and MEC (Kalappa et al., 2011; Li and Yang, 2007; Uteshev and Smith, 2006), and they were applied to the bath for $5 \mathrm{~min}$. ACh was applied to the bath perfusion $5 \mathrm{~min}$ before and 5 min after the ATR or MEC.

\subsection{Statistical analysis}

All data are expressed as the means \pm SEM. Statistical analyses were performed using SigmaPlot statistics programs (version 11.0; Systat Software Inc., San Jose, CA, USA). To evaluate the effects of different doses of ACh on the membrane potential of NTS neurons we applied Student's $t$ test. Responses to ACh before and after the antagonists were compared using Student's paired $t$-test. In all cases, a $\mathrm{p}$ value of $<0.05$ was used for statistical significance.

\section{Conflict of interest}

The authors declare no conflicts of interest.

\section{Acknowledgements}

This research was supported by Brazilian public funding from the Conselho Nacional de Desenvolvimento Científico e Tec- 
nológico (CNPq) to DC and EC, Fundação de Amparo a Pesquisa do Estado de São Paulo (FAPESP 2011/20040-1, 2010/17218-0; 2009/54888-7; 2012/05844-0) to DSAC, EC and WF and Canadian Institutes of Health Research Grant (MOP12192) to AVF.

\section{References}

Abdala, A.P., Schoorlemmer, G.H., Colombari, E., 2006. Ablation of NK1 receptor bearing neurons in the nucleus of the solitary tract blunts cardiovascular reflexes in awake rats. Brain Res. 1119, 165-173.

Andresen, M.C., Kunze, D.L., 1994. Nucleus tractus solitarius-gateway to neural circulatory control. Annu. Rev. Physiol. 56, 93-116.

Blanch, G.T., Freiria-Oliveira, A.H., Murphy, D., Paulin, R.F., Antunes-Rodrigues, J., Colombari, E., Menani, J.V., Colombari, D.S., 2013. Inhibitory mechanism of the nucleus of the solitary tract involved in the control of cardiovascular dipsogenic, hormonal, and renal responses to hyperosmolality. Am J. Physiol. Regul. Integr. Comp. Physiol. 304, R531-R542.

Cheng, P.W., Lu, P.J., Chen, S.R., Ho, W.Y., Cheng, W.H., Hong, L.Z., Yeh, T.C., Sun, G.C. Wang, L.L., Hsiao, M., Tseng, C.J., 2011. Central nicotinic acetylcholine receptor involved in Ca2+-calmodulin-endothelial nitric oxide synthase pathway modulated hypotensive effects. Br. J. Pharmacol. 163, 1203-1213.

Ciriello, J., Hochstenbach, S.L., Roder, S., 1994. Central projections of baroreceptor and chemoreceptor afferents fibers in the rat. In: Barraco, I.R.A. (Ed.), Nucleus of the Solitary Tract, CRC Press, Boca Raton, Florida, pp. 35-50.

Colombari, E., Menani, J.V., Talman, W.T., 1996. Comissural NTS contributes to pressor responses to glutamate injected into the medial NTS of awake rats. Am. J. Physiol. 270, R1220-R1225.

Cottle, M.A., 1964. Degeneration studies of the primary afferents of IXth and Xth cranial nerves in the cat. J. Comp. Neurol. 122, 329-345.

Criscione, L., Reis, D.J., Talman, W.T., 1983. Cholinergic mechanisms in the nucleus tractus solitarii and cardiovascular regulation in the rat. Eur. J. Pharmacol. 88 47-55.

da Silva, L.G., Dias, A.C., Furlan, E., Colombari, E., 2008. Nitric oxide modulates the cardiovascular effects elicited by acetylcholine in the NTS of awake rats. Am. J. Physiol. Regul. Integr. Comp. Physiol. 295, R1774-R1781.

Dhar, S., Nagy, F., McIntosh, J.M., Sapru, H.N., 2000. Receptor subtypes mediating depressor responses to microinjections of nicotine into medial NTS of the ra. Am. J. Physiol. Regul. Integr. Comp. Physiol. 279, R132-R140.

Ernsberger, P., Arneric, S.P., Arango, V., Reis, D.J., 1988. Quantitative distribution of muscarinic receptors and choline acetyltransferase in rat medulla: examination of transmitter-receptor mismatch. Brain Res. 452, 336-344.

Feng, L., Sametsky, E.A., Gusev, A.G., Uteshev, V.V., 2012. Responsiveness to nicotine of neurons of the caudal nucleus of the solitary tract correlates with the neuronal projection target. J. Neurophysiol. 108, 1884-1894.

Feng, L., Uteshev, V.V., 2014. Projection target-specific action of nicotine in the caudal nucleus of the solitary tract. J. Neurosci. Res. 92, 1560-1572.

Furuya, W.I., Bassi, M., Menani, J.V., Colombari, E., Zoccal, D.B., Colombari, D.S., 2014 Differential modulation of sympathetic and respiratory activities by cholinergic mechanisms in the nucleus of the solitary tract in rats. Exp. Physiol. 99, 743758 .

Gotts, J., Atkinson, L., Edwards, I.J., Yanagawa, Y., Deuchars, S.A., Deuchars, J., 2015. Co-expression of GAD67 and choline acetyltransferase reveals a novel neuronal phenotype in the mouse medulla oblongata. Auton. Neurosci.

Helke, C.J., Handelmann, G.E., Jacobowitz, D.M., 1983. Choline acetyltransferase activity in the nucleus tractus solitarius: regulation by the afferent vagus nerve. Brain Res. Bull. 10, 433-436.

Kalappa, B.I., Feng, L., Kem, W.R., Gusev, A.G., Uteshev, V.V., 2011. Mechanisms of facilitation of synaptic glutamate release by nicotinic agonists in the nucleus of the solitary tract. Am. J. Physiol. Cell Physiol. 301, 347-361.

Li, D.P., Yang, Q., 2007. Membrane and synaptic properties of nucleus tractus solitarius neurons projecting to the caudal ventrolateral medulla. Auton. Neurosci. 136, 69-81.

Machado, B.H., 2001. Neurotransmission of the cardiovascular reflexes in the nucleus tractus solitarii of awake rats. Ann. N.Y. Acad. Sci. 940, 179-196.

Miura, M., Reis, D.J., 1972. The role of the solitary and paramedian reticular nuclei in mediating cardiovascular reflex responses from carotid baro- and chemoreceptors. J. Physiol. 223, 525-548.

Palkovits, M., Zaborsky, L., 1977. Neuroanatomy of central cardiovascular control. Nucleus tractus solitary: afferent and efferent neuronal conecctions in relation to baroreceptor reflex arc. In: Hypertension and Brain Mechanisms. Vol., W. De Jong, A.P. Provoost, A.P. Shapiro (Eds.) Elsevier, Amsterdam, pp. 9-34.

Sapru, H.N., 1996. Carotid chemoreflex. Neural pathways and transmitters. Adv. Exp. Med. Biol. 410, 357-364.

Schreihofer, A.M., Anderson, B.K. Schiltz J.C. Xu, L, Sved, A.F. Stricker, F.M. 1999. Thirst and salt appetite elicited by hypovolemia in rats with chronic lesions of the nucleus of the solitary tract. Am. J. Physiol. 276, R251-R258.

Shihara, M., Hori, N., Hirooka, Y., Eshima, K., Akaike, N., Takeshita, A., 1999. Cholinergic systems in the nucleus of the solitary tract of rats. Am. J. Physiol. 276, R1141-R1148.

Shiraki, T., Toyoda, A., Sugino, H., Hori, A., Kobayashi, S., 1997. Possible nicotinic receptor-mediated modulation of synaptic transmission in nucleus of the solitary tract. Am. J. Physiol. 272, R869-R873.

Simon, J.R., Oderfeld-Nowak, B., Felten, D.L., Aprison, M.H., 1981. Distribution of choline acetyltransferase, acetylcholinesterase, muscarinic receptor binding, and choline uptake in discrete areas of the rat medulla oblongata. Neurochem. Res. 6, 497-505.

Talman, W.T., Perrone, M.H., Reis, D.J., 1980. Evidence for L-glutamate as the neurotransmitter of baroreceptor afferent nerve fibers. Science 209, 813-815.

Tsukamoto, K., Yin, M., Sved, A.F., 1994. Effect of atropine injected into the nucleus tractus solitarius on the regulation of blood pressure. Brain Res. 648, 9-15.

Ueno, S., Kakehata, S., Akaike, N., 1993. Nicotinic acetylcholine receptor in dissociated rat nucleus tractus solitarii neurons. Neurosci. Lett. 149, 15-18.

Uteshev, V.V., Smith, D.V., 2006. Cholinergic modulation of neurons in the gustatory region of the nucleus of the solitary tract. Brain Res. 1084, 38-53.

Wada, E., Wada, K., Boulter, J., Deneris, E., Heinemann, S., Patrick, J., Swanson, L.W. 1989. Distribution of alpha 2, alpha 3, alpha 4, and beta 2 neuronal nicotinic receptor subunit mRNAs in the central nervous system: a hybridization histochemical study in the rat. J. Comp. Neurol. 284, 314-335. 